Experiencias juveniles en escenarios de inclusión digital

Belén Fernández Massara

Revista Argentina de Estudios de Juventud, (12), e022, diciembre 2018

ISSN 1852-4907 | https://doi.org/10.24215/18524907e022

https://perio.unlp.edu.ar/ojs/index.php/revistadejuventud

FPyCS | Universidad Nacional de La Plata

La Plata | Buenos Aires | Argentina

\title{
EXPERIENCIAS JUVENILES \\ EN ESCENARIOS DE INCLUSIÓN DIGITAL
}

\author{
Youth Experiences in Digital Inclusion Scenarios
}

Belén Fernández Massara

bfernand@soc.unicen.edu.ar

https://orcid.org/0000-0002-9389-0377

Facultad de Ciencias Sociales

Universidad Nacional del Centro de la Provincia de Buenos Aires

Argentina

\section{Resumen}

Palabras clave En este trabajo, la autora analiza las transiciones que emprenden los sujetos juveniles

mediaciones tecnológicas

experiencias juveniles identidades inclusión digital

\section{Keywords}

technological mediations youth experiences

identities digital inclusion hacia experiencias sostenidas de apropiación de las tecnologías interactivas, encuadradas en el Programa Conectar Igualdad en dos etapas (2011 a 2013 y 2014-2015). La propuesta metodológica recupera las mediaciones tecnológicas en sus diversas dimensiones. Se aborda un caso considerado emblemático, la educación secundaria técnica en Olavarría (Buenos Aires, Argentina), a partir de registrar los cambios y las permanencias que definen estos actores en la diversidad de sus actuaciones cotidianas.

\section{Abstract}

In this work, the author analyzes the transitions that youth subjects undertake towards sustained experiences of appropiation of interactive technologies, framed in the Conectar Igualdad Program in two stages (2011 to 2013 and 2014-2015). The methodological proposal recovers technological mediations in its various dimensions. A case considered emblematic, the technical secondary education in Olavarría (Buenos Aires, Argentina), registering the changes and permanence that define these actors in the diversity of their daily actions.

Recibido 27/03/2018

Aceptado 14/07/2018 


\title{
EXPERIENCIAS JUVENILES \\ EN ESCENARIOS DE INCLUSIÓN DIGITAL
}

\author{
Por Belén Fernández Massara
}

Hay un indudable proceso de desterritorialización, un quiebre del centro con respecto a la periferia, el discurso del mercado se globaliza, irrumpen Internet y sus redes virtuales, pero solo para relocalizarse, reterritorializarse, es decir, para establecer nuevas coordenadas. Reguillo Cruz (2012)

Las políticas públicas de inclusión digital en América Latina han despertado especial interés en el campo de la comunicación / cultura. Por una parte, por cuanto renuevan los debates acerca de cómo las tecnologías de la información y la comunicación (TIC) inciden, significativamente, en los diversos ámbitos de la vida social. Por otra, con vistas a dimensionar los alcances concretos de tales propuestas en materia educativa, por los desafíos que representa su implementación para el conjunto de los actores involucrados y en el marco de sus particulares determinaciones históricas. Frente a ello, el Estado nacional está llamado a recuperar su rol protagónico para habilitar condiciones de verdadera transformación socioeducativa que resulten alternativas a la retórica dominante del mercado.

Estas preocupaciones registran importantes antecedentes a nivel global. Durante la Cumbre Mundial de la Sociedad de la Información, impulsada por la Organización de las Naciones Unidas, y realizada en Ginebra (2003) y en Túnez (2005), se discutieron numerosos aspectos: entre ellos, la situación del sistema educativo frente a la urgencia de incorporar masivamente las tecnologías para paliar las desigualdades sociales. El concepto sociedad del conocimiento -acuñado por Peter Drucker, en 1969- fue adoptado por la UNESCO (Organización de las Naciones 
Unidas para la Educación, la Ciencia y la Cultura) con el fin de superar los aspectos instrumentales y de incluir los cambios ligados a la producción, la circulación y la apropiación de los conocimientos. No obstante, como advierte Armand Mattelart (2003), la sociedad del conocimiento es también problemática: conforme a cierto difusionismo tecnológico, relega el análisis crítico de las variables que promueven una marginación creciente entre los países, y al interior de cada uno, adecuándose a los parámetros del neoliberalismo económico.

Es nuestro propósito en este artículo analizar las mediaciones tecnológicas en tanto dimensión de la problemática TIC / educación, en el marco del Programa Conectar Igualdad ( $\mathrm{PCl}$ ), impulsado en la Argentina por el gobierno de la presidenta Cristina Fernández de Kirchner (Decreto 459/10). El PCl constituye la política de inclusión digital con mayor relevancia en las últimas décadas, con orientaciones similares a otras iniciativas en la región, como el Plan CEIBAL implementado en Uruguay. El imperativo de «normalizar» una política educativa tensiona las realidades escolares en las condiciones emergentes de modernidad líquida, en transiciones culturales cada vez más fluidas e imprevisibles (Bauman, 2013). En especial en la actualidad, cuando las transformaciones de estas políticas públicas se anticipan con características desfavorables o, al menos, de creciente complejización. ${ }^{1}$

El trabajo que aquí se presenta invita a comprender los niveles de intensidad de apropiación y de uso, moderados pero significativos, que emprenden los actores en sus relaciones con las TIC. Nos centramos, para esto, en las prácticas y en las representaciones que expresan los sujetos juveniles, y problematizamos la cuestión de las mediaciones tecnológicas en los contextos educativos. Se recuperan consideraciones de la investigación a la que responden la tesis doctoral defendida recientemente (FPYCS-UNLP) $^{2}$ y las indagaciones enmarcadas en el Núcleo de Actividades Científico-Tecnológicas (FACSO-UNICEN). ${ }^{3}$ Abordan ambos las problemáticas vinculaciones entre TIC, educación y construcción de ciudadanía, sobre la base del análisis textual y el método comparativo constante. El estudio longitudinal comprende dos etapas del PCI, según su implementación efectiva (2011-2013 y 20142015), en el caso de la educación secundaria técnica de la ciudad de Olavarría (Buenos Aires, Argentina), a partir del análisis de dos Escuelas de Educación Secundaria Técnica (EEST): la EEST N. ${ }^{0}$ 1, «Dr. René Favaloro», y la EEST N. ${ }^{0}$ 2, «Luciano Fortabat». 
A pesar de su importancia clave, la educación técnica ha sido escasamente abordada en este campo. Sus establecimientos educativos fueron los primeros en recibir las netbooks bajo el modelo 1 a 1, en continuidad con el modelo provincial para escuelas técnicas. Hay que considerar, además, las condiciones razonablemente distintivas de lo que la antropología urbana ha calificado como "ciudad de rango intermedio" (Gravano, 2016). El partido de Olavarría cuenta con 111.320 habitantes, distribuidos en la ciudad y en 19 pequeñas localidades serranas. Una de las principales es Villa Alfredo Fortabat, así llamada en alusión a su fundador, hijo menor de Luciano Fortabat. También conocida como Loma Negra, la villa se pobló masivamente con la llegada de familias inmigrantes que buscaban trabajo en la fábrica cementera del mismo nombre. Con esta localidad conectan buena parte de las características estructurales y simbólicas de Olavarría, mitologizadas en el modelo socioeconómico desarrollista - en la actualidad plenamente en crisis (la producción primaria minera y cementera) - como «ciudad del trabajo» o «del cemento». Sobre esas imágenes residuales se sostienen los esfuerzos de recuperación de la educación técnica, tras el deterioro resultante de las sucesivas reformas neoliberales de la década del noventa.

De acuerdo a lo analizado, el supuesto dominante que orienta las adecuaciones del $\mathrm{PCl}$, es la construcción imaginaria sobre la formación técnica como espacio natural de introducción de tecnología. Una aceptación generalizada, a menudo preñada de determinismo, refuerza esa percepción del rol de las TIC en el proyecto formador, anclado en la doble temporalidad pasado / futuro del desarrollo socioproductivo. Frente a esto, nos preguntamos, entonces, si los y las jóvenes escolarizados/as, desde sus particulares experiencias interactivas, devienen capaces de poner en discusión la larga hegemonía de estos imaginarios.

\section{Mediaciones tecnológicas}

\section{y experiencias juveniles: apuntes teóricos}

Las políticas públicas de inclusión digital adquieren centralidad en los estudios sobre comunicación en la Argentina, en el marco más amplio de la problemática TIC/educación. Particularmente, la Facultad de Periodismo y Comunicación Social (FPYCS) de la Universidad Nacional de La Plata (UNLP) viene desarrollando en los 
últimos años diversos materiales que se orientan a comprender críticamente las oportunidades inclusivas o de cambio educativo que entraña la tecnología, a partir de los esfuerzos de implementación del PCI.

Se destacan dos informes de evaluación sobre el impacto pedagógico, institucional y social del PCI llevados adelante por universidades nacionales, entre ellas, la UNLP. En el primero, publicado en 2011, once universidades presentaron un conjunto de reflexiones que determinaron, entre otros aspectos, que los y las jóvenes se sentían motivados/as, reconocidos/as en sus saberes y partícipes del mejoramiento de la convivencia escolar, en tanto directivos y docentes advertían la necesidad de capacitación profesional que acompañara y que brindara recursos para la integración pedagógica. Una segunda etapa del PCl estaría centrada en este aspecto. Hacia 2015, un total de quince universidades avanzaron en ese análisis. Se confirmó que las netbooks no desplazaban las tecnologías tradicionales, sino que se complementaban con ellas. Los y las estudiantes las calificaron como facilitadoras, valoraron los beneficios de la propiedad personal, y una mayor cooperación y horizontalidad en los procesos de comunicación implicados en el aprendizaje.

También impulsado por la línea de Seguimiento y Evaluación del PCl, un trabajo realizado durante 2011 en el marco del Proyecto «óvenes cronistas populares» de la UNLP, indagó en los usos y las apropiaciones que realizaban los y las jóvenes por fuera del ámbito escolar. Sus testimonios dieron cuenta de un gran repertorio de acciones mediadas por las netbooks, vinculadas al entretenimiento, por un lado, y a las actividades escolares, por otro, al tiempo que ilustraron su importancia para reducir las desigualdades sociales. Otras investigaciones revelaron, también, la personalización de la tecnología como factor de igualación entre los sectores populares. Por ejemplo, la conectividad supliría la ausencia de una habitación individual en cuanto espacio tan caro para los procesos de identificación juveniles. A partir de estas indagaciones, se concluye que, en ocasiones, los cuestionamientos al PCl pueden ser interpretados como una defensa de privilegios sobre los que se sustenta y se legitima la dominación (Benítez Larghi, 2013, 2016).

Mención aparte merece la articulación entre el Centro de Investigación y Desarrollo en Comunicación, Industrias Culturales y Televisión (FPYCS-UNLP) y la Facultad de Arquitectura, Arte y Comunicación de la Universidad de la Provincia de San Pablo, Brasil. El libro publicado (Novomisky \& Américo, 2016) destaca la urgencia de implementar dispositivos de capacitación docente y de democratizar 
Internet: las escuelas aún adolecen en buena parte de condiciones de conectividad que permitan potenciar la utilidad de los equipos del PCI. Finalmente, los debates surgidos durante el taller «Estrategias de Trabajo Colaborativo con Redes Sociales Virtuales y otros Asistentes Online», resultaron en la publicación de dos libros producidos por el equipo de cátedra junto con los y las estudiantes. De acuerdo con María Victoria Martín y Pamela Vestfrid (2015, 2018), recuperar las narrativas populares en términos de experiencias de apropiación y de resignificación favorece entre los y las jóvenes su rol creativo y no de mero consumo, como partícipes y productores/as de la era digital.

A partir de considerar estos antecedentes, recuperamos las mediaciones como un vasto campo problemático. A partir del concepto medular propuesto por Jesús Martín-Barbero (2008), las mediaciones tecnológicas conciernen a las matrices culturales que definen las múltiples experiencias de apropiación que interpelan a los sujetos «íntima y estructuralmente mediados por sus interacciones desde y con la tecnología» (p. 222). Allí se materializa ese desplazamiento de las TIC en sí mismas a sus modos de acceso, de apropiación y de uso; de su incidencia en abstracto a los procesos de imposición y de dependencia, de dominación pero también de negociación, de resistencia y de resemantización. A partir de sus exploraciones sobre la Media Ecology, Carlos Scolari (2008) reformula este concepto en tanto hipermediaciones, a las que define como la trama de procesos de intercambio, de producción y de consumo simbólico que involucra gran cantidad de sujetos, de medios y de lenguajes tecnológicamente interconectados de manera reticular. En estas particulares interfaces se producen la convergencia de los dispositivos, las mutaciones de las percepciones de tiempo y de espacio, las nuevas modalidades interpretativas y las posibilidades para producir y para intercambiar contenidos en la web.

En sus estudios sobre recepción, Guillermo Orozco Gómez (1993) observa que los usuarios interpelan sustancialmente a la convergencia digital, desafiando las lógicas del mercado y produciendo cambios en la circulación y en la reproducción de la información. En sus esfuerzos por operacionalizar los conceptos seminales vertidos por Martín-Barbero, formula una tipología sobre la base de una noción más amplia de mediaciones múltiples. A pesar de sus orígenes en torno a las audiencias televisivas y de sus distintos desarrollos teóricos, el modelo continúa siendo válido para abordar las mediaciones tecnológicas. 
En síntesis, se comprenden: las mediaciones individuales (a partir de considerar al individuo como sujeto cognitivo y emotivo, que desarrolla estrategias personales para luego emprender comunidades interpretativas con otros y otras); mediaciones situacionales (dado que los hábitos, los valores y los modelos que se manifiestan en las situaciones de uso inciden de manera decisiva en esas interacciones); las mediaciones institucionales (las instituciones escolares, los medios o la familia, definen valores y normas que concurren también en la definición de pautas de apropiación); las mediaciones video-tecnológicas (relacionadas con los mecanismos, las formas de codificación, las gramáticas y los lenguajes específicos); y las mediaciones de referencia (aquellas que determinan intereses, hábitos y modalidades de lectura, de acuerdo a género, edad, clase social o lugar de residencia).

Las mediaciones, así definidas, pueden perder de vista las diversas determinaciones de las identidades, los espacios y las temporalidades a partir de los cuales se reconstruyen los sentidos propuestos por los medios masivos. Este sesgo es consistente con sus derivaciones de la etnografía de audiencias, si bien durante los últimos años los Estudios Culturales han insistido en la necesidad de inscribir la comprensión de los contextos situacionales en entramados sociohistóricos más amplios (Morley, 2008). Así y todo, las mediaciones múltiples adquieren notable vigencia para entender las relaciones con las TIC. Por caso, expresan las intrincadas vinculaciones entre nuevos y viejos medios, al tiempo que ejercen condicionamientos importantes sobre cómo son percibidos, adoptados y utilizados por las personas, y cómo estas incurren, desde allí, en distintas configuraciones identitarias.

A nuestros fines, el análisis comprende cuatro grandes mediaciones: cognitivas, institucionales, situacionales y lingüístico-comunicativas. La mayoría de las indagaciones sobre las interacciones de los sujetos con las TIC adolece de una cuestión central: comprender las instituciones donde estas se producen, a las que necesariamente complejizan o ponen en tensión dialéctica. En este sentido, las realidades estructural-simbólicas de las dos escuelas técnicas analizadas son radicalmente distintas. ${ }^{4}$ Sin ser este un estudio comparativo, focalizar en estas diferencias nos permite confirmar la relevancia de las mediaciones institucionales como categoría analítica y problematizadora, a la vez que someter a discusión las características pretendidamente homogéneas atribuidas a las culturas juveniles. 
Resultante del análisis y de acuerdo a los lineamientos de la teoría fundamentada, asumimos que las mediaciones tecnológicas no remiten ni a artefactos ni a saberes estrictamente instrumentales, sino a los nuevos modos de percepción y de lenguaje, a las narrativas y las sensibilidades que ponen en juego las tecnologías interactivas en esas particulares situaciones de uso. Este aspecto debe articularse en una categoría aún más general y en clave sociohistórica, que comprenda las matrices culturales en las que se materializan los modos de apropiación y de uso tecnológicos, y que revelan estrategias específicas de aprendizaje, de participación social y de adscripción identitaria desde las cuales se negocian y se reconstruyen los sentidos hegemónicos de la sociedad del conocimiento.

Estas mediaciones entraman en las experiencias culturales a través de las cuales los y las jóvenes logran visibilizar sus demandas, elaborar sus narrativas y reconocer formas específicas de agenciamiento. En este punto, la cuestión de la edad no se agota en el referente biológico, conforme a las aproximaciones de los estudios de juventud. Aunque no ahondaremos en este aspecto, vale decir que «ser joven» no es una categoría cerrada: queda relativizada cuando se abordan sus lugares de pertenencia, aquellos que implican importantes y cada vez más diversos anclajes identitarios. La moda, la música, el acceso a objetos tecnológicos, configuran modos de entender el mundo, «bajo la tensión identificacióndiferenciación; efecto simbólico - pero no por ello menos real- de identificarse con los iguales y de diferenciarse de los otros, en especial de los adultos» (Reguillo Cruz, 2012, p. 24).

Áreas de indagación como la autopercepción de los saberes previos y los esquemas mentales implicados, las ventajas o las desventajas atribuidas al uso digital y la dicotomía escuela técnica / escuela media, nos permiten afirmar que las mediaciones cognitivas no son estrictamente individuales. Convocan interpretaciones personales y colectivas, resultantes de trayectorias compartidas, de lugares diferenciados y de singulares negociaciones con los modelos dominantes. Dos cuestiones clave podemos añadir a las particularidades de nuestro caso: a) una formación articulada en torno a la especificidad técnica del conocimiento, las orientaciones curriculares, la diferencia taxativa con la escuela media y, con el tiempo, la implementación del 7mo. año y las prácticas 
profesionalizantes; y b) la jornada extendida, que profundiza las relaciones cotidianas con los talleres y las áreas técnicas, y también el registro simbólico donde la escuela se reconoce como lugar estructurante de socialización.

A pesar de ser los destinatarios directos del PCl, los y las jóvenes entrevistados/as no se sienten verdaderamente interpelados más que en relación con la distribución de los equipos, en tanto «la netbook» aparece como síntesis discursiva de la inclusión digital, pero también de sus contradicciones. Si ya las tecnologías (teléfonos celulares, otros dispositivos informáticos) tenían una presencia sostenida en su vida social, empiezan a adquirir valoraciones negativas si distraen de aquello que merece verdadero esfuerzo: el conocimiento escolar. Las representaciones aparecen disociadas de las prácticas, por cuanto utilizan concretamente la netbook durante el horario de clases para divertirse, para comunicarse o para hacer más amena la jornada, pero tales experiencias se califican como irreconciliables con las escolares, demandantes de otros niveles de concentración y de un compromiso intelectual y creativo más agudo.

La dicotomía tiempo escolar / tiempo de ocio constituye un poderoso organizador de los usos tecnológicos de jóvenes y de adultos y adultas. La netbook como elemento distractivo en el aula implica la capacidad de racionalizar al conocimiento como objeto de una apropiación, a la vez que reproduce una mirada descalificadora sobre las potencialidades pedagógicas de las TIC, más allá de los usos instrumentales. Pero los y las estudiantes comprenden tempranamente que las netbooks comportan usos responsables. Resistir la autoridad docente, llevarse la materia, no hacer nada, distraerse, perder el tiempo, constituyen todos núcleos conceptuales que articulan un campo semántico negativo.

Para estas estudiantes, el «buen uso» expresa dos dispositivos con función de negociación, moralizante o directamente disciplinadora: la comunicación entre pares y las normas institucionales. La ausencia de regulaciones conlleva la necesidad de autocontrol y de control grupal:

El profesor le decía: «Cerrá la compu, cerrá la compu, cerrá la compu. Si no la cerrás, te jodés vos». No le decía así, pero nos dábamos cuenta, jaja. El año pasado, un compañero no hacía nada. Era una materia en la que teníamos que hacer las cosas en el día, y él no hacía nada. Era por la computadora, pero más por él (6 to. año, Orientación Química, EEST N. ${ }^{0}$ 1). 
Creo que se tendrían que poner firmes para que los chicos no usen las computadoras para conectarse a Facebook. Porque a veces se perjudican ellos, porque no prestan atención, porque no entregan los trabajos y después vienen los trimestres. Deberían bloquear el Facebook. ¿Por qué no se bloqueó? No sé (6to. año, Orientación Química, EEST N. ${ }^{0}$ 1).

Internet constituye un campo de problematizaciones. Los y las estudiantes no logran elucidar plenamente sus propias competencias, aunque interpretan el valor de la intervención docente para desarrollar estrategias de búsqueda, de selección y de utilización de los datos. En gran medida, las posibilidades de navegación dependen de las características objetivas, cognitivas y curriculares de la materia. Hay cierto consenso en torno a que los talleres demandan un uso intensivo de las computadoras.

Puede objetarse la inclusión digital si no va acompañada no tanto por un saber técnico-disciplinar sino por un saber didáctico, que contribuya a superar los riesgos del «facilismo», de un uso poco provechoso.

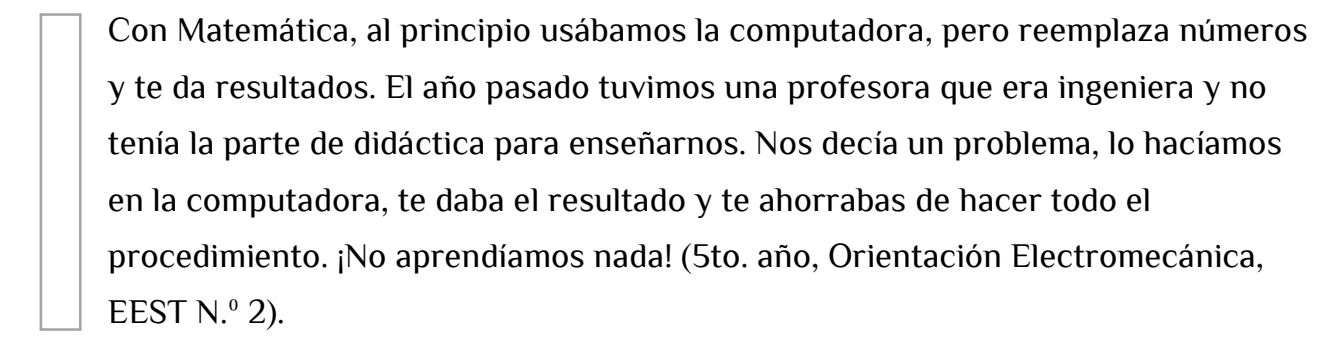

En la segunda etapa, otros modos de concientización atribuyen sentidos relativamente distintos a la tensión hacer / no hacer. Por ejemplo, PowerPoint deja de ser solo un recurso expositivo, en reemplazo de la pizarra, para implicar actividades de producción de conocimientos. Durante la observación de un trabajo grupal, se registró una presentación audiovisual, que incluía imágenes sobre productos, mapas conceptuales y una diversidad de contenidos investigados en libros y en Internet. Un entorno interactivo supone la utilización de representaciones gráficas que favorecen procesos de percepción simbólica, al tiempo que descripciones verbales, sobre la base de habilidades guiadas en la selección, la clasificación y el procesamiento de la información. En términos de Nicholas C. 
Burbules y Thomas A. Callister (2001), la organización hipertextual de Internet, su aparente fragmentación y atomización, puede derivar en naufragio cognitivo o bien generar contratos de lectura cada vez más comprensivos.

Ahora bien, examinar el valor de la tecnología, entender sus códigos, identificar sus componentes y sus modos de funcionamiento, y utilizarla a los fines de cada materia, no exime al profesor o a la profesara de un riguroso seguimiento. En el «control» de los usos prevalece el valor de la autoridad docente como el de la netbook en tanto instrumento auxiliar, pero se trata de un proceso que también comporta la idea de un espacio áulico razonablemente ordenado. Tales nociones desafían tanto los modelos verticalistas de enseñanza como el carácter «espontáneo» de los saberes asociados a las TIC. Los y las estudiantes de la EEST N. ${ }^{0} 2$ suelen mostrarse especialmente demandantes, lo que confirma ciertos posicionamientos personales atravesados por los ordenamientos institucionales con alto grado de estructuración, pero constantemente negociados.

El ex presidente del Centro de Estudiantes establece comparaciones con otras realidades escolares:

Tengo amigos que van a UNICEN [escuela secundaria] y con los profesores las usan mucho. Tienen una materia en la que aprenden a editar videos y usan mucho PowerPoint. Y usan justamente mucho este programa con el que el profesor controla lo que hacen y les manda el material por ahí (7mo. Año, Orientación Electromecánica, EEST N. 2.)

Ante los equipos averiados y los problemas de conectividad, los discursos juveniles privilegian los aspectos cognitivos ligados al ejercicio docente por sobre la cuestión del acceso, algo especialmente destacado de esta etapa. Los tipos y los niveles de conocimientos producidos dependerán de las capacidades técnicas pero, a la vez, de las disciplinares y las pedagógicas. En un solo caso, de la totalidad de las entrevistas realizadas, apareció referenciado el tema de la edad. Para esta estudiante de 2do. año de la EEST $\mathrm{N}^{0}{ }^{0}$ 2, sin embargo, lo que incide fundamentalmente es el conjunto de iniciativas, de saberes y de disposiciones de su docente, antes que las diferencias generacionales. Tampoco la formación técnica es un factor determinante: «La profe es joven, tal vez tiene que ver, porque entienden más cómo bajar del AP, entienden más sobre las tecnologías». 
Como ha reflexionado Raymond Williams (1980), la cultura constituye un proceso poderoso que se halla ligado a continuidades prácticas como las instituciones, que no son meras imposiciones ideológicas sino elementos efectivamente vividos. En estas condiciones, los sujetos juveniles dan cuenta de sus formas de experimentar -resignificándolas- las relaciones estrechas entre TIC, conocimiento y enseñanza. A medida que la implementación del PCl avanza, para los jóvenes la función docente ya no deviene centralmente en control de los usos digitales, sino en lugar evocador de saberes profesionales que puedan hacer de la tecnología un capital provechoso, un ambiente interactivo y no solamente una herramienta de aprendizaje. Al decir de Delia Crovi Druetta (2013), la capacidad de los usuarios para expresarse y para gestionar una gran cantidad de contenidos es prueba evidente de la doble dimensión técnica-cultural de estas innovaciones, puestas al servicio de la creatividad humana.

\section{Lo que median las instituciones:}

«ser grasas» o que la escuela «quede linda»

En estos entramados se juegan las posibilidades de adecuación del PCl: la importancia asignada a la institución como mediadora de creencias y de usos específicos es directamente proporcional a la fuerza ideológica de sus tradiciones. Constituye este un aspecto de las vinculaciones íntimas entre tecnologías e identidades culturales. Ahora bien, repensar esta dimensión requiere de detenernos, brevemente, en las bases ontológicas de Cornelius Castoriadis (2003), quien reflexiona que solo mediante la institución de la sociedad se puede salir del caos de la potencia imprevisible que conlleva la imaginación radical, ese «magma» constante, contingente e imprevisible que es para él la esencia de la creación humana. El orden de lo histórico-social se presenta como creación de instituciones que son la encarnación de las significaciones imaginarias sociales, sin reconocer otro origen que la institución misma. En ellas se realiza la tensión entre las estructuras dadas, lo instituido, y lo que estructura, lo instituyente. 
De acuerdo con Daniel Cabrera (2006), las tecnologías convocan el conjunto de imágenes, representaciones, afectos y deseos en constante movimiento, una totalidad coherente (con relativo cierre) de creencias y, a la vez, una matriz de significados compartidos a partir de la cual la sociedad se autorepresenta y se instituye como tal. El imaginario tecnocomunicacional instituye a las tecnologías como portadoras de las utopías y las esperanzas en un progreso natural e inevitable. Revela su fundamental dimensión ideológica cuando la sociedad del conocimiento desencadena fuerzas simbólicas que impulsan a actuar en un sentido dado, a adaptarse a sus requerimientos. Una conciencia crítica en torno a estas condiciones ha de poner en cuestión los discursos hegemónicos que justifican a priori la incorporación de las TIC, en las cuales se apoyan las promesas de la modernización tecnoeducativa.

Durante todo el período analizado, la EEST N. ${ }^{\circ} 1$ atravesó sucesivos cambios de autoridades directivas: desde la debilidad de la gestión, pasando del "caos» al «autoritarismo» (cuyo correlato necesario es una identidad negativa), hacia los esfuerzos de reconversión de la cultura institucional. En la primera etapa de análisis, los y las estudiantes evidenciaron ser plenamente conscientes de las situaciones que experimentaban: los problemas de aprendizaje, el deterioro edilicio, los niveles persistentes de estigmatización por pertenecer a "esta escuela», por vivir en «este barrio». Pero, a diferencia de las adultas y los adultos, no se resignaban a las condiciones de desventaja a las que parecían destinados/as. Aunque no se reduce a ello, la netbook (la primera de acceso personal y con frecuencia, de la familia) los igualaba material e imaginariamente a otros y a otras.

A modo de síntesis, nos centraremos en el siguiente discurso, que comprende la densidad conflictiva de esos escenarios, a partir de dos contradicciones observadas. La primera alude a los mecanismos de control y está representada en la figura del entonces Director. Un dispositivo de panóptico, en términos foucaultianos, condensa para estos y estas jóvenes las condiciones de discriminación que sufren, la vigilancia de sus actos, la autoridad verticalista y arbitraria, la sensación de no ser escuchados. 
A veces viene el profesor y nos dice: «Ciérrenla». ¡Ahora quieren poner cámaras! Si las ponen las vamos a sacar. Eso viene de Dirección... Las cosas igual deberían cambiar, porque la otra Directora no era muy recta, digamos. No ponía las reglas que tenía que poner. Ahora con este Director llegás tarde y ya te mira raro (5to. año, Orientación Electrónica, EEST N. . 1).

Esta situación contrasta con el estado de acefalía que caracterizó a la gestión anterior, pero de ningún modo resuelve los problemas de funcionamiento. ${ }^{5}$ Entre ellos, los y las entrevistados/as incluyen, paradójicamente, sus propios comportamientos, en actitud desafiante tanto ante la ausencia de normas como ante el ejercicio de poder que se percibe como injusto. La «indisciplina», nudo de una construcción identitaria negativa, es objeto de constantes desplazamientos. Cuando falla la escuela como objeto de apropiación, la que emerge como tal es el aula, donde se negocian los sentidos de la autoridad pedagógica y el conjunto de "concesiones» relativas a la presencia de la netbook: "Y sí, hacía falta... [poner reglas]. Porque tenemos todo... En nuestra aula tenemos tele, equipo de música, ping pong... No para la hora de clase, claro, pero si faltan veinte minutos el profesor nos da permiso» (5to. año, Orientación Electrónica, EEST N. 1). El uso recreativo desalienta la incorporación de tecnología con intencionalidad didáctica, pero expresa entre los y las estudiantes una conciencia material sobre la complejidad de estos contextos en los que se muestran capaces de realizar otro tipo de aprendizajes.

La segunda contradicción involucra una trama abigarrada de imágenes, que actualizan el viejo proyecto de la educación técnica y sus relaciones dilemáticas con formas culturales emergentes. Sirven para enfrentar o para compensar las diferencias de inclusión que plantean la mayoría de las instituciones tradicionales, lo que incluye a la propia escuela. Pero el proyecto de la movilidad social, ligado a la preparación para el mundo del trabajo, se articula imaginariamente con las expectativas de los estudios superiores. A diferencia de sus docentes, estos jóvenes en situación de vulnerabilidad social no quieren resignar el proyecto aspiracional que supone la universidad: «Acá igual han egresado chicos que ahora son ingenieros. La calidad educativa es buena. A lo mejor habría que mejorar la disciplina» (5to. año, Orientación Electrónica, EEST N. 1). 
En las valoraciones de los grupos avanzados de la EEST N.$^{\circ}$ 2, la universidad constituye el proyecto natural, asociado a su pertenencia social. Pero lo que experimentan en tiempo presente es la red afectiva que los conecta orgánicamente entre sí y con la institución. Por una parte, las adecuaciones del PCl configuran un panorama difuso, donde prima la continuidad respecto de los usos previos de las computadoras; por otra, cierta reticencia acerca de cómo vienen a impactar estas innovaciones en los formatos tradicionales en los cuales las y los estudiantes instituyen el sentido de sus trayectorias, su lugar en el mundo. Ese plano afectivo se manifiesta en el reconocimiento compartido como «grasas»:

Los que estamos acá, estamos porque amamos la escuela. Tenés que estar en esta escuela, y si estás en una especialidad que te gusta, seguro que no te vas a distraer con otras cosas. A mí me gusta lo que estudio y lo que hago, entonces no me voy a distraer con una página (6to. año, Orientación Informática, EEST N. ${ }^{0} 2$ ).

Asociadas a lógicas de autoafirmación, estas representaciones se asientan en una doble temporalidad: el presente, donde se conjuga el sentimiento de pertenencia, y el pasado mitificante, cristalizado en la ciudad, una memoria compartida que deriva de la herencia de los padres, muchos de ellos egresados de la escuela. El legado de la fraternidad alimenta un propósito distintivo de continuidad generacional: comunicar a los más jóvenes la importancia dinamizante de estas tradiciones.

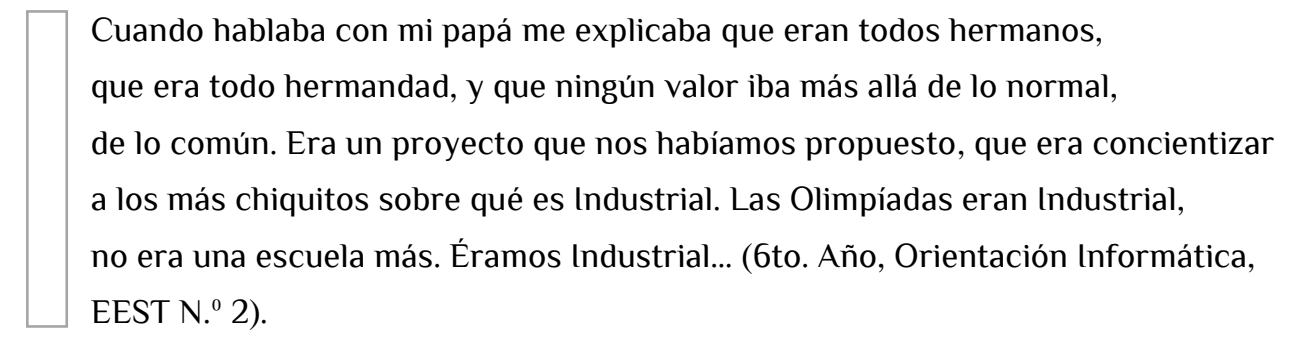

Estas afiliaciones se continúan en la segunda etapa. Si las familias influyen de modo ostensible, para los y las estudiantes comenzar y sostener sus trayectorias resulta de decisiones personales: «Industrial», como aún se la conoce, es una escuela que «se elige». Por una parte, esta evoca los imaginarios urbanos ligados a la «ciudad del trabajo", por equivalencia semántica trabajo / industria. Por otra, constituye el «filtro», real e imaginario, que discrimina a sus alumnos y alumnas según sus desempeños $\mathrm{y}$, sobre todo, acorde a su capacidad para adaptarse a los ordenamientos escolares. Este cierre siempre precario del orden de lo simbólico 
redunda en formas implícitas pero eficaces de exclusión. Parafraseando a Richard Hoggart (2013), se trata de indagar en el trasfondo de las actitudes entre ellos / excluidos y nosotros / incluidos: la discriminación opera sobre esos «otros y otras» jóvenes que no logran apropiarse de esa cultura plenamente vivida.

Yo pienso que esta escuela no es para cualquiera. ¡Te tiene que gustar! Porque es una escuela técnica, porque pasamos muchas horas del día. $Y$ ahora tenemos $7 m o$. año. La mayoría elegimos la escuela, hay gente que viene solo porque le queda cerca, pero esos son los que se van de la escuela o se quedan (repiten). Esos no eligieron la escuela... (5to. Año, Orientación Electromecánica, EEST N. ${ }^{0}$ 2).

La EEST N. ${ }^{0} 1$ se encuentra atravesada por los esfuerzos de reconversión, especialmente valorados por los y las estudiantes mayores que han vivido las gestiones erráticas de los sucesivos equipos directivos. Ese marco interpretativo reside en la defensa de la escuela como un territorio propio que comienza a resistir el deterioro material y simbólico, y su imagen pública tradicionalmente estigmatizada. Los cambios en la estructura curricular, el 7mo. año a partir del cual egresan con título de técnicos, dotan de mayor especificidad a la formación y la igualan imaginariamente con la EEST N. ${ }^{0}$ 2. $\mathrm{Y}$ a la par de sus docentes, estos y estas jóvenes contribuyen a las transiciones hacia un paradigma alternativo, aquel que detenta rasgos relativamente diferenciados y verificables en la práctica.

Si la escuela comienza a ser esbozada como lugar válido de afiliación, el peso de la mirada externa resulta determinante y alienta las transformaciones que en los últimos años constituyen su principal proyecto: lograr el mejoramiento institucional y socioeducativo. «Sí, puede ser que la identidad tenga que ver con la escuela. Yo estoy orgulloso de pertenecer a la escuela, otro aspecto, otro ambiente, que quede linda, presentable, porque antes no era así» (6to. año, Orientación Química, EEST N. ${ }^{0}$ 1). Otro aspecto reside en las preocupaciones sobre el futuro personal, de acuerdo a dos posiciones: proyectar la posibilidad de continuar los estudios superiores y poner en valor la formación laboral, operando un distanciamiento respecto de las carreras universitarias. Expresión novedosa de la tensión ellos / nosotros, respectivamente, ingenieros / técnicos, que apela a la centralidad de los saberes técnico-profesionales: 
Acá seguimos trabajando. Es interesante, por eso estamos haciendo las pasantías, estamos en empresas, se va generando una relación que ayuda a que nos vayan teniendo en cuenta, a que nos llamen cuando salgamos de acá. Nos han dicho que hay muchos ingenieros pero pocos técnicos, y lo que hacemos nosotros no lo hacen los ingenieros (7mo. año, Orientación Electrotécnica, EEST N. ${ }^{0} 1$ ).

Martín-Barbero (2015) ha argumentado que lo que prevalece en las juventudes actuales es un replanteamiento de las formas de continuidad cultural. Vincula esta etapa con aquella que Margaret Mead había calificado como prefigurativa. Por contraste a las etapas posfigurativa y cofigurativa, esta entraña un profundo quiebre generacional: los aprendizajes dependen menos del legado de sus padres, que de las relaciones con sus pares y de sus propias exploraciones del mundo que habitan. Sobre esta base suele atribuirse a los jóvenes saberes enteramente novedosos. No obstante, registran, antes que fracturas absolutas, continuidades y discontinuidades con respecto a generaciones anteriores. Sumado a ello, los procesos de desterritorialización devienen en procesos de reterritorialización: las TIC están fundamentalmente mediadas por las trayectorias escolares y las relaciones que se establecen con ellas habilitan a tensar esos territorios heredados y a descubrir otros, como espacios vitales de la cultura.

\section{Las TIC en situación:}

\section{del dominio técnico al uso interactivo}

Un nudo problemático desde los inicios del PCl es la dependencia digital. Los juegos en red y las redes sociales configuran vitales experiencias juveniles, pero se ponderan como contrarias al aprendizaje escolar. Es necesario relativizar el «fanatismo» que una mayoría de los adultos y las adultas les atribuyen, porque tales usos representan diversas racionalidades simbólicas: lo importante no es tanto el acceso personal, sino los gustos que definen particulares estéticas, narrativas y subjetividades en situaciones cotidianas. En esta clave operan patrones ligados a la interactividad, que desafían los usos instrumentales que prioriza la escuela: «Algunos tienen cargados juegos, como el Counter, yo no, a mí no me gusta, jaja. La uso bastante, para chatear, por las redes sociales o para buscar información que nos piden en la escuela» (6to. año, Orientación Maestro Mayor de Obra, EEST N. 2). 
En el contexto del aula, la netbook convive con otros soportes, aunque esa interacción no suele conducir a la innovación didáctica. Las materias técnicas tienden a privilegiar el dominio instrumental, mientras que en otras áreas el uso es escaso o se limita a aplicaciones básicas. Los y las estudiantes tampoco observan diferencias significativas entre leer en pantalla o en papel, escribir en la carpeta o en el procesador de textos; las ventajas percibidas consisten en ahorrar fotocopias o en buscar información, que luego guardan en la netbook o copian en la carpeta. Aquello que despierta mayores expectativas no es Internet sino los software, lo que replica cierta concepción restringida a las aplicaciones operativas de las netbooks, no solo debido a las interpretaciones del PCI sino en línea de continuidad con los modos tradicionales de integración de tecnología; en especial, el modelo de laboratorio.

Sin embargo, aunque para los alumnos y las alumnas operar un programa que resuelve operaciones matemáticas puede ser «fácil» queda claro que no conduce necesariamente a «aprender». Porque lo preponderante no es el programa sino las prácticas, aquellas que revelan una creciente predisposición a utilizar de manera complementaria los distintos soportes en los procesos de enseñanza-aprendizaje. La netbook asume un lugar completamente distinto si los ejercicios se realizan, primero, manualmente y, luego, son revisados a través del software, lo que puede potenciar los procesos de autonomía, de autocorrección y de seguimiento.

En la segunda etapa de análisis, se obtuvo que los y las estudiantes perciben una utilización todavía acotada de las netbooks y de otras tecnologías, problemas que se continúan como las fallas técnicas y los retrasos en el sistema de reparaciones. Evalúan que la falta generalizada de capacitación trae como consecuencia los temores de los y las docentes a perder autoridad, lo que desalienta las inclusiones digitales en las clases. A menudo, esto conduce a justificar estas sensaciones generalizadas. Desde estas representaciones, se muestran dispuestos a la hora de ayudar a sus profesores y profesoras en el uso operativo de la netbook, un proceso percibido como aprendizaje colaborativo y sumamente enriquecedor en espacios más dialógicos.

Estas posibilidades, además, contradicen los discursos moralizantes acerca de que «los chicos no leen», así como la idea igualmente naturalizante de que solo leen o quieren leer en las pantallas. La mayoría demanda una inclusión más frecuente e intensiva de las netbooks para determinados usos; no obstante, prefieren leer en las 
fotocopias. Los cursos superiores marcan una diferencia, debido a sus grupos más reducidos y a la disponibilidad de otros soportes, en el marco de mediaciones situacionales donde interactúan netbooks, tablets, celulares, carpetas y libros. Una estudiante de 6to. año (Orientación Química, EEST N.o 1) consideró que estas actividades evitan «perder el tiempo», algo que se considera superado, o bien ligado al horario extraescolar. En suma, las TIC pueden ser legítimamente utilizadas, siempre y cuando estén subordinadas a la dinámica áulica y bajo fines estrictamente educativos.

Nos preguntamos si el momento de la trayectoria educativa tiene particular incidencia en las actuaciones de los más jóvenes (Educación Secundaria Básica, de 1ro. a 3er. año), quienes empiezan a recibir las netbooks en esta segunda etapa. Por cierto, permanecen con ellas todo el tiempo, a veces en horario de clases, enmarcados en esa "euforia» inicial que produce abiertas tensiones con los adultos y las adultas. Pero, de manera progresiva, empiezan a experimentan otro tipo de relaciones. Una posición de indiferencia o de subestimación resulta más frecuente en la EEST N.² 2, según los propósitos de las materias y las iniciativas de sus docentes.

Se usa muy poco, muy de vez en cuando, y cuando la usamos es para hacer trabajos prácticos que no se estudian. $\mathrm{O}$ una actividad, no un texto que tenga que ser estudiado. Y... sería lo mismo que en la carpeta, pero si no estuviera sería lo mismo. La usamos porque está (2do. año, Formación General, EEST N. 2).

Lo que subyace es el desfasaje entre las prácticas escolares y las del tiempo libre, o entre los niveles de propiedad digital: «La netbook del PCl» y «Mi netbook». Los intereses personales escapan a las generalizaciones. Pueden motivar la producción de contenidos, una apropiación mediada por las orientaciones de la educación técnica, pero que demuestra, a muy temprana edad, autonomía personal y capacidad reflexiva sobre lo que tales usos implican:

A mí me gusta hacer juegos, estoy empezando a hacer en 3D, siempre me interesó, por eso sigo Informática, porque quiero aprender los lenguajes informáticos. La netbook se puede usar, pero uso más mi compu, tengo la mía, la notebook (2do. año, Formación General, EEST N. 2). 
Con notables excepciones, los videojuegos, las redes sociales y las experiencias similares constituyen un área de intervención y de experimentación didáctica poco explorada, que los y las estudiantes no logran evaluar plenamente en sus relaciones con los contenidos escolares. No obstante, en la pluralidad de los usos que efectivamente realizan avanzan hacia formas alternativas de aprender. En consecuencia, reducir las TIC al mero consumo impide una comprensión más acabada de procesos de apropiación que podrían aprovecharse eficazmente en la enseñanza. De acuerdo con Morley (2008), resulta imperativo indagar no solamente en las prácticas sino en los significados que los usuarios de diversa condición cultural les otorgan a esas prácticas, «cómo son percibidas, interpretadas y utilizadas y cómo son diferencialmente vistas (o soslayadas) por sus consumidores potenciales como relevantes (o no) para ellos» (p. 193).

\section{Mediaciones lingüístico-comunicativas:}

modelos heredados, lenguajes convergentes

Siguiendo con Martín-Barbero (2015), lo que parece caracterizar a las culturas juveniles es el profundo dis-locamiento y des-centramiento de los saberes, asociados a la conversación oral, a la combinación de códigos, y a las estéticas y las narrativas ligadas al hipertexto. Estas mediaciones tienden a profundizarse tanto por los modos en los que las netbooks irrumpen en las aulas, como por la condición de portabilidad que habilita distintas manifestaciones de la personalización. En consonancia con otras investigaciones, los discursos analizados confirman el hecho de que los y las jóvenes realizan «unos usos que les permiten percibirse simbólicamente como incluidos (en algo más que el entorno digital, en el mundo social actual, en aquello de lo cual todos hablan y hacen)» (Cabello, 2017, p. 19).

En el tiempo de ocio, el acceso físico representa, primeramente, un mundo privado que no se comparte con las familias, a contramano de los efectos multiplicadores previstos por el PCI. Como dijimos, entre alumnos de la EEST N. ${ }^{\circ} 1$ la netbook suele ser la primera computadora personal, en tanto la escuela es el lugar casi excluyente de acceso a Internet. Sin embargo, el entusiasmo inicial puede decantar en acostumbramiento. La sensación de desapego tenderá a agudizarse con el paso del tiempo, produciendo formas más complejas de igualación: 


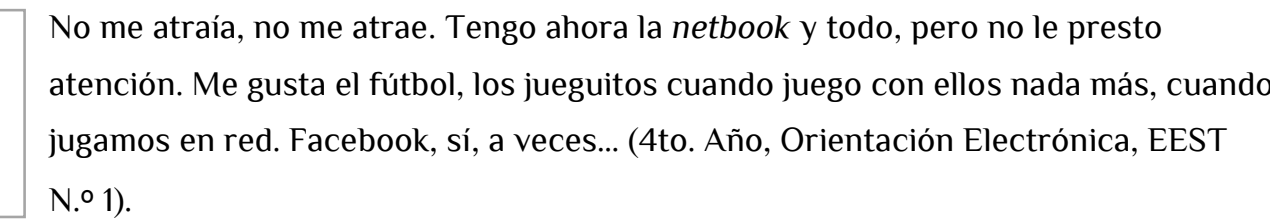

La cuestión de lo privado se altera, fundamentalmente, cuando se refiere al aprendizaje escolar. En las comparaciones entre la netbook y la carpeta, las ventajas de una constituyen las desventajas de la otra. El lugar de materialización de lo producido lo ocupa, casi de manera excluyente, la carpeta: más práctica, segura o «ńntima». Los temores a perder ese conocimiento almacenado contrastan con la sensación de seguridad anclada en la estabilidad del papel, una idea extendida en la EEST N.० 2:

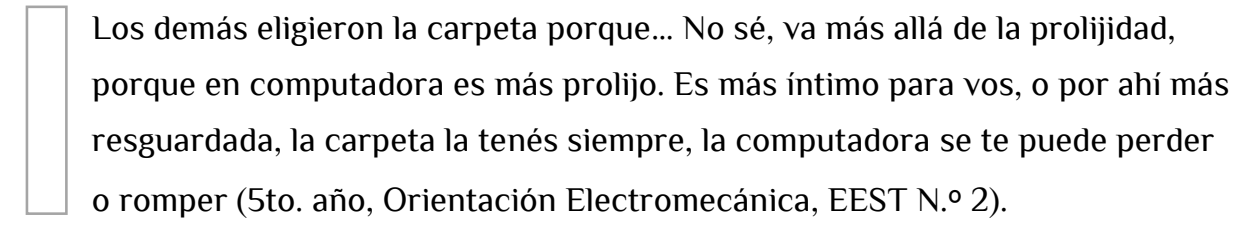

Los contenidos y los criterios de acreditación, los materiales que requieren, las modalidades de enseñanza-aprendizaje que las orientan y las estructuran, constituyen a las asignaturas en gramáticas de producción de saberes, a la vez que en depositarias de un mundo de afectos, de intereses y de preocupaciones desde los cuales los y las estudiantes esgrimen las razones para incorporar (o no) las netbooks al trabajo escolar. En esta etapa se restringen a las áreas técnicas. Los conceptos negativos sobre jugar y chatear recrean los supuestos de que las relaciones con las TIC son valiosas, placenteras o divertidas, pero conforme a los fines educativos deben involucrar una utilización más consciente y responsable.

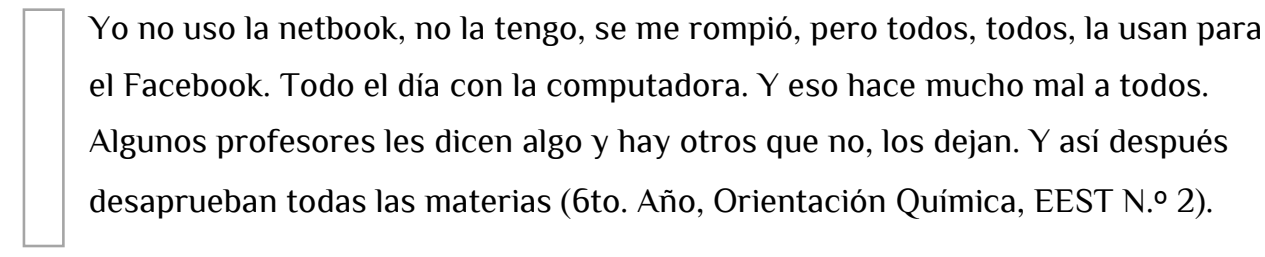

$\mathrm{Si}$ es cierto que los entornos tecnológicos dinamizan las múltiples narrativas ligadas al hipertexto, estas coexisten con textualidades ligadas a la cultura letrada, determinadas tanto por mediaciones escolares como por preferencias personales. Por ejemplo, escribir en las carpetas o imprimir los textos, habitualmente atribuidas 
a los adultos y las adultas. Los y las estudiantes pueden sentirse abrumados con la presencia de la computadora, como lo evidencia una referencia frecuente en la orientación Informática de la EEST N. 2: «Todos los días usamos la computadora... A mí no me gusta usar la computadora en las materias de aula. Porque me cansa, prefiero la carpeta» (6to. año). La apropiación simbólica del libro sirve de resistencia ante actividades repetitivas y poco estimulantes: «Estamos todo el día con la computadora! Y cuando venís a la escuela te dan ganas de hacer otra cosa. Bueno, vamos a buscar en libros, vamos a escribir...» (6to. año).

Durante la segunda etapa del $\mathrm{PCl}$, la familia continúa teniendo un lugar preponderante en el mundo afectivo, si bien esto no se replica en una utilización compartida: «Antes igual teníamos computadora en casa, Internet, pero esta es mía» (3er. año, Formación General, EEST N.o 1). Pero entre estudiantes avanzados de la misma escuela emergen diversas apreciaciones, entre ellas, el desapego afectivo que antes encontrábamos solo entre los grupos de la EEST N. 2, que relegan a las netbooks como herramientas para el aprendizaje. Por un lado, el acceso a otros dispositivos móviles ha tenido un crecimiento exponencial en los últimos años y atraviesa todos los segmentos sociales, como los teléfonos celulares o los smartphones. Por otro, las interacciones con las distintas tecnologías se fundan en las diferencias renovadas entre lo escolar y lo extra-escolar; de ahí que la apropiación personal puede estar ligada a otros equipos: «En cambio, la mía la tengo a mi nivel, o uso el iPod» (6to. Año, Orientación Química, EEST N.²).

Además de las distinciones entre materias técnicas y de área, los y las estudiantes mayores centran su atención en las transiciones hacia el ciclo superior. Capaces de valorar estos cambios desde sus propias trayectorias, validan los conocimientos específicos de la formación técnica como la adquisición de códigos necesarios en un marco de socialización. Las apropiaciones del espacio institucional y las relaciones interpersonales a ellas asociadas se ven complejizadas por las relaciones con las TIC.

Tenemos un lugar, el sucucho, jajaja. Ahí nos juntamos a charlar, jugamos al ping pong. Nos gusta el compañerismo, que veces no se ve en otras escuelas. $Y$ algunos nos quedamos a comer, y ves a los chiquitos sentados con las computadoras, piensan que están para jugar. Se les informa, sí, miren que esto es para hacer actividad... (6to. Año, Orientación Electromecánica, EEST N.o 2). 
Fomentar prácticas tecnológicas maduras y convenientes ligadas a la «actividad» en contraposición al «jugar» comprende desplazamientos imaginarios entre las relaciones horizontales que se ponderan y cierta mirada dominante sobre los compañeros más jóvenes. La consigna es concientizarlos hacia la adopción de normativas, consensuadas pero recreadas desde la práctica, que dictaminen cómo moverse en esos espacios, cuáles son las acciones que están habilitadas y cuáles son causales de sanción, qué valores las orientan, cómo mejorar el compromiso con la identidad institucional.

Estas matrices significantes intersectan con las valoraciones que hacen del profesorado. El proceso de refortalecimiento de la EEST N. ${ }^{\circ} 1$ se torna visible porque atañe al clima del aula, a una estructura institucional organizada, a modelos comunicacionales más flexibles y participativos, y a relaciones empáticas que unen a jóvenes y adultos/as en un mismo proyecto. Las resistencias de algunos y algunas docentes a estos cambios socavan las bases de su autoridad, proyectando sentimientos de descalificación o de desconfianza mutua donde convergen los usos de las tecnologías, y les impide entender la necesidad genuina de los y las adolescentes de mantener contacto con sus hogares a lo largo de toda una jornada escolar, lo que refuta la opinión generalizada sobre la ausencia de los padres o la ruptura generacional con ellos.

Hay profesores que vienen enojados y enseguida te sacan las computadoras, que copiemos en la carpeta. Pero en mi casa no tengo Internet, así que aprovecho acá. Yo estaba hablando con mi vieja, porque vivo lejos, y me cagó a pedos. No... que estás chateando todo el día. Y le expliqué que estaba haciendo el trabajo, mire, estoy trabajando... (5to. Año, Orientación Electrónica, EEST N.o 1).

En tanto, en el 7mo. año las prácticas profesionalizantes definen una etapa final, ahora obligatoria. En la EEST N. ${ }^{\circ} 1$ suele tratarse de grupos acotados debido a los altos niveles de deserción, por lo cual construyen este trayecto en términos de autoconfirmación, de triunfo personal y emotivo. Las tensiones tiempo escolar / tiempo libre se mantienen, pero asociadas a las ansiedades que suscita la sobrecarga de actividades, la preparación para el mundo del trabajo y la proximidad a la vida adulta. 
A la mañana tenemos las prácticas: yo en Loma Negra, ellos (dos compañeros) en Ferrosur, al mediodía. Bueno, yo antes trabajaba, ahora no, así que me quedo, y a la tarde tenemos los talleres, a las 4 . De 1 a 4 dormimos, yo hago deportes así que entreno. Para el tiempo libre tenemos celulares, ahora tendrían que mandar tablets, bah, no sé, igual es incómoda, te seguís manejando con el celular (7mo. Año, Orientación Electromecánica, EEST N. ${ }^{\circ}$ 1). ${ }^{6}$

A los teléfonos se les atribuye una serie de rasgos positivos que antes solo calificaban para las netbooks: propiedad, portabilidad, practicidad, conectividad, entre otros. Los desplazamientos hacia el uso pedagógico derivan del deterioro de las netbooks y de la conexión deficiente, como de nuevas experiencias donde las pantallas se reconcilian con la explicación oral, la pizarra y la carpeta, el mate y la música. En estas interfaces cobran sentido las contradicciones comprendidas en la integración de las TIC:

\footnotetext{
$\square$ Por eso usamos los celulares, que están prohibidos, pero incluso los profesores nos dejan usar los celulares. Pero ¿para qué tenemos las computadoras si tenemos que usar los celulares? (4to. Año, Orientación Informática, EEST N. 2).
}

Tematizar las mediaciones implica asumir que la educación formal no puede quedar aislada de los entornos tecnológicos, en especial cuando la convergencia deja de ser cuestión de mera convivencia, las diferentes retóricas abandonan sus respectivas ventanas en la pantalla y se contaminan entre sí, haciendo emerger espacios híbridos que dan lugar a otras formas de comunicación (Scolari, 2009). Asumido esto, el carácter completamente inédito o transformador que suele atribuirse a estos lenguajes merece examinarse con mayor prudencia. Porque expresan permanentes negociaciones con los modos heredados de leer y de escribir, de conocer y de comunicarse, y resignifican las orientaciones de la inclusión digital de acuerdo con objetivos personales y en la diversidad de situaciones socioculturales en las que intervienen.

\section{Apuntes finales}

En un contexto de transformaciones aceleradas, cobra fuerza la pregunta por las políticas públicas con el objeto de avizorar alcances y limitaciones de la integración 
de las tecnologías interactivas. Un componente imprescindible de iniciativas como Conectar Igualdad, radica en reconocer en toda su complejidad las demandas culturales, sociales y pedagógicas delos agentes educativos. En base a ello, nos hemos detenido en los modos de transitar estos cambios por parte de los sujetos juveniles, examinando las mediaciones tecnológicas como categoría problemática y articuladora. Esta propuesta habilita una lectura más global que trasciende al aula, para atender a los procesos de institucionalización del modelo 1 a 1. Así, lo cotidiano se afinca en el plano histórico desde donde se reconstruyen estas configuraciones escolares, frente a lo cual las instituciones afrontan los dilemas de su propia reconversión como proyecto colectivo y efectivamente realizable.

Las TIC dinamizan procesos de reterritorialización porque anclan lo global en experiencias plenamente localizadas, pero también porque la escuela aún constituye un fundamental enclave identitario. En este marco, intenta conciliar esta doble temporalidad: el proyecto del «deber ser», moderna, funcional, adecuada a las complejas transformaciones del sistema social a cuyos requerimientos responde; y el relato de "volver a ser», de recuperar su especificidad técnico-profesional, activando imágenes residuales sobre las premisas de la inclusión, la movilidad y la formación laboral con las que históricamente ha construido la frontera con la escuela media.

Las oportunidades de la inclusión digital se ven atravesadas por los ejes de identificación y de diferenciación que los y las adolescentes desplazan permanentemente, una construcción nosotros / ellos desde la cual instituyen muy diversas formas de exclusión y afirman sus sentidos de pertenencia. La EEST N.० 2 es «Industrial», utopía de lo que la educación técnica debe ser (y volver a ser), pero se experimenta en presente como escuela «viva». En estas múltiples temporalidades desborda sus límites, para restaurar la potencia evocadora de los imaginarios residuales de Olavarría como «ciudad del trabajo». En agudo contraste, la EEST N.o 1 semiotiza un círculo vicioso: una digitalización precaria parece agudizar los problemas identitarios, e impide valorar y aprovechar las posibilidades del acceso a las TIC. Lo notable es que son los y las estudiantes quienes comienzan a reclamar ese territorio compartido que reconocen en los otros, a resistir la marca negativa de su imagen pública, como la falsa antinomia entre desorden y autoritarismo, entre la debilidad institucional y los mecanismos de control desde los cuales la escuela ha intentado resolver infructuosamente una identidad fallida. 
Con la progresiva normalización del $\mathrm{PCl}$, no exenta de tensiones, los procesos de mejoramiento institucional acompañan y motorizan actuaciones novedosas: cuando las TIC dejan de ser meras herramientas para operar hacia transformaciones favorables de las redes de comunicación, dentro y fuera del aula. Si bien incipientes, algunas experiencias de integración pedagógica parecen apuntar en esa dirección. Al mismo tiempo, permiten negociar los imaginarios urbanos en los procesos de resurgimiento de la formación técnica, asociados tradicionalmente al desarrollo científico-tecnológico.

Pensar nuevas estrategias de inclusión digital implicaría trazar objetivos concretos a partir de diagnósticos de situación de las instituciones. Entre otros aspectos, comprender los saberes informales que los adolescentes generan cotidianamente en sus interacciones con las $\mathrm{TIC}$, donde conviven múltiples textualidades, desde las hipertextuales hasta las asociadas a la carpeta y el libro, la música y la televisión. Tampoco ellos/as reconocen esas prácticas como un capital cultural valioso, al margen del entretenimiento. Asumido este contraste, entienden que las actividades escolares reclaman usos responsables y criteriosos, a la vez que orientaciones docentes más estimulantes. En contraposición a las sobreestimaciones así como a las miradas prejuiciosas, advierten que la centralidad de estos cambios no radica en la tecnología en sí misma. Lo que importa es su potencial para promover modalidades de apropiación en atención a su dimensión cognitiva, emotiva y social, que anime a los actores a establecer vínculos pedagógicos de nuevo tipo, y relaciones más genuinas y democratizadoras con el conocimiento.

\section{Referencias}

Bauman, Z. (2013). Modernidad líquida. Madrid, España: Fondo de Cultura Económica.

Benítez Larghi, S. (2013). Lo popular a partir de la apropiación de las TIC. Tensiones entre representaciones hegemónicas y prácticas.

Question, (38), 215-229. Recuperado de http://perio.unlp.edu.ar/ojs/index.php/question/article/view/1813/1575 
Benítez Larghi, S. (2016). Elogio de un «fracaso». La dimensión simbólica del Programa Conectar Igualdad. Revista Argentina de Estudios de Juventud (10), 1-15. Recuperado de https://perio.unlp.edu.ar/ojs/index.php/revistadejuventud/article/view/ $3732 / 3749$

Burbules, N. C. y Callister, T. A. (2001). Riesgos y promesas de las nuevas tecnologías de la información. Madrid, España: Granica.

Cabello, R. (2017). La comprensión de los vínculos que establecemos con las tecnologías. En R. Cabello y A. López (Eds.), Contribuciones al estudio de procesos de apropiación de tecnologías (pp. 11-21). Ciudad Autónoma de Buenos Aires, Argentina: Gato Gris / Red de Investigadores sobre Apropiación de Tecnologías.

Cabrera, D. (2006). Lo tecnológico y lo imaginario. Las nuevas tecnologías como creencias y esperanzas colectivas. Ciudad de Autónoma de Buenos Aires, Argentina: Biblos.

Cambios y continuidades en la escuela secundaria. Las universidades públicas conectando miradas (2015). Recuperado de https://www.educ.ar/recursos/126462/cambios-y-continuidades-en-laescuela-secundaria-la-universidad-publica-conectando-miradas

Castoriadis, C. (2003). La institución imaginaria de la sociedad II. Ciudad Autónoma de Buenos Aires, Argentina: Tusquets.

Conectar Igualdad. Apropiaciones de las netbooks por fuera del ámbito escolar (2011). Recuperado de https://drive.google.com/file/d/0BG45aqy96bVd1dlaUIINFFOZ0U/view

Crovi Druetta, D. (2013). Repensar la apropiación desde la cultura digital. En S. Morales y M. I. Loyola (Comps.), Nuevas perspectivas en los estudios de comunicación. La apropiación tecno-mediática (pp. 1123). Ciudad Autónoma de Buenos Aires, Argentina: Imago-Mundi. 
Decreto 459 (2010). Créase el Programa "Conectar Igualdad. Com. Ar" de incorporación de la nueva tecnología para el aprendizaje de alumnos y docentes. Recuperado de http://servicios.infoleg.gob.ar/infoleglnternet/anexos/165000169999/165807/texact.htm

Decreto 1239 (2016). Transfiérese el «PROGRAMA CONECTAR IGUALDAD.COM.AR». Recuperado de http://servicios.infoleg.gob.ar/infolegInternet/anexos/265000269999/268713/norma.htm

Decreto 386 (2018). PLAN APRENDER CONECTADOS. Recuperado de http://servicios.infoleg.gob.ar/infoleglnternet/anexos/305000309999/309610/norma.htm

Gravano, A. (2016). Tres hipótesis sobre las relaciones entre sistema urbano e imaginarios de ciudades media. En A. Gravano, A. Silva y S. Boggi (Comps.), Ciudades vividas. Sistemas e imaginarios de ciudades medias bonaerenses (pp. 69-90). Ciudad Autónoma de Buenos Aires, Argentina: Café de las Ciudades.

Hoggart, R. (2013). La cultura obrera en la sociedad de masas. Ciudad Autónoma de Buenos Aires, Argentina: Siglo XXI.

La Nación (30 de noviembre de 2011). Prohíben instalar cámaras de seguridad en escuelas de la provincia de Buenos Aires. Recuperado de https://www.lanacion.com.ar/sociedad/prohiben-instalar-camaras-deseguridad-en-escuelas-de-la-plata-nid1428859

Martín, M. V. y Vestfrid, P. (2015). La aventura de innovar con TIC: aportes conceptuales, experiencias y propuestas. Recuperado de http://perio.unlp.edu.ar/sites/default/files/la_aventura_de_innovar_con _tic.pdf 
Martín, M. V. y Vestfrid, P. (2018). La aventura de innovar con TIC II: aportes conceptuales, experiencias y propuestas. Recuperado de http://sedici.unlp.edu.ar/bitstream/handle/10915/78640/Documento_co mpleto.pdf-PDFA.pdf?sequence=1\&isAllowed=y

Martín-Barbero, J. (2008). Lo público: experiencia urbana y metáfora ciudadana. Cuadernos de Información y Comunicación, (13), 213-226. Recuperado de http://revistas.ucm.es/index.php/CIYC/article/view/CIYC0808110213A 17247

Martín-Barbero, J. (2015). ¿Desde dónde pensamos la comunicación hoy? Chasqui. Revista Latinoamericana de Comunicación, (128), 13-29. Recuperado de http://chasqui.ciespal.org/index.php/chasqui/article/view/2545/2445

Mattelart, A. (2003). La sociedad de la información. El enfrentamiento entre proyectos de sociedad. Diálogos de la Comunicación, (67).

Morley, D. (2008). Medios, modernidad y tecnología. Barcelona, España: Gedisa.

Novomisky, S. y Américo, M. (Comps.). Convergencia: medios, tecnologías y educación en la era digital. Recuperado de https://libros.unlp.edu.ar/index.php/unlp/catalog/view/615/582/2068-1

Nuevas voces, nuevos escenarios: estudios evaluativos sobre el Programa Conectar Igualdad (2011).Informe de evaluación de Conectar Igualdad, Argentina. Recuperado de http://repositorio.educacion.gov.ar/dspace/handle/123456789/96946

Orozco Gómez, G. (1993). Dialéctica de la mediación televisiva. Estructuración de estrategias de recepción por los televidentes. Anàlisi (15), 31-44. Recuperado de https://www.raco.cat/index.php/Analisi/article/view/41180 
Reguillo Cruz, R. (2012). Culturas juveniles. Formas políticas del

desencanto. Ciudad Autónoma de Buenos Aires, Argentina: Siglo XXI.

Scolari, C. (2008). Hipermediaciones. Elementos para una teoría de la comunicación digital interactiva. Barcelona, España: Gedisa.

Scolari, C. (2009). Alrededor de la(s) convergencia(s). Conversaciones

teóricas, divergencias conceptuales y transformaciones en el

ecosistema de medios. Signo y Pensamiento, (54)XXVIII, 44-55.

Recuperado de file:///C:/Users/user/Downloads/4527-

Texto\%20del\%20art\%C3\%ADculo-16357-2-10-20131213.pdf

Williams, R. (1980). Marxismo y literatura. Barcelona, España: Península.

Notas

1 La continuidad de las políticas de inclusión digital abre nuevos interrogantes. En 2016, el gobierno de Mauricio Macri transfirió el PCl, junto con Primaria Digital, a la órbita de Educ.ar (Decreto 1239/16). En tanto, en mayo de 2018 se creó el Plan Aprender Conectados (Decreto 386/18), en reemplazo del modelo 1 a 1. Si bien en el texto de la norma se indica que el Plan apunta a promover una «estructura y equipamiento tecnológico mucho más poderoso» no se precisan ni sus fundamentos ni las orientaciones en materia educativa.

2 En el marco del Doctorado en Comunicación de la Facultad de Periodismo y Comunicación Social de la Universidad Nacional de La Plata.

3 El grupo «Producciones e investigaciones comunicacionales y sociales de la ciudad intermedia» (PROINCOMSCl) es un Núcleo de Actividades Científico-Tecnológicas (NACT), consolidado a partir de su reconocimiento por el Consejo Superior de la Universidad Nacional del Centro de la Provincia de Buenos Aires (UNICEN).

4 Quienes asisten a la EEST N. ${ }^{0}$ 1, «Dr. René Favaloro», pertenecen a sectores socioeconómicos menos favorecidos y presentan dificultades de desempeño escolar. A la EEST N. ${ }^{0}$ 2, "Luciano Fortabat» (llamada así en honor a su fundador), aún se la denomina industrial, término que condensa el legado de la fábrica Loma Negra y de la Fundación Fortabat. Es la institución más numerosa y reconocida; sus estudiantes provienen de sectores medios y medio-altos y mantienen con ella una fuerte identificación. Mientras tales 
particularidades se mantienen en este caso, la EEST N. ${ }^{0} 1$ comenzará a atravesar un proceso sostenido de mejoramiento institucional en todos sus niveles.

5 Finalmente, esa medida no fue implementada. Generó agudas controversias y recibió el pronunciamiento en contra de toda la comunidad educativa. Un caso conocido se produjo en la ciudad de La Plata, en 2011, cuando la justicia provincial resolvió obligar al Municipio «a que de manera inmediata se abstenga de permitir la existencia y/o proveer la instalación de todo dispositivo de registro-video en cualquier espacio o establecimiento educativo departamental» (La Nación, 30/11/2011).

6 La fábrica Loma Negra tiene presencia vital en toda la educación secundaria técnica, tanto por el apoyo brindado a una escuela en su época fundacional como por el hecho de que constituye uno de los espacios preponderantes de ejercicio de las prácticas profesionalizantes, en el caso de la otra. Resulta aún hoy definitoria del perfil de Olavarría como polo industrial, atribuyéndole su marca identitaria como ciudad intermedia. Ferrosur Roca S.A. es una empresa argentina de sector ferroviario, actualmente de capitales privados, que tiene la concesión sobre el manejo y la infraestructura de trenes de carga de Ferrocarril General Roca. De manera similar, articula orgánicamente con el pasado emblemático de desarrollo, especialmente de la industria cementera. 